УДК 796 и 37.037.1

https://doi.org/10.36906/FKS-2021/22

Гимазов Р.М.

ORCID: 0000-0001-5200-2321, канд. пед. наук;

Попова А.К.

Сургутский государственный педагогический университет,

2. Сургут, Россия

\title{
ВЛИЯНИЕ ФИЗИЧЕСКИХ НАГРУЗОК НА ПСИХОЭМОЦИОНАЛЬНОЕ СОСТОЯНИЕ ДЕТЕЙ С НАРУШЕНИЕМ ИНТЕЛЛЕКТА
}

Аннотация. В статье представлены результаты проведенного стабилометрического исследования по выявлению влияния физических нагрузок на детей с нарушениями интеллекта, занимающихся в КОУ «Сургутская школа для обучающихся с ограниченными возможностями здоровья». Проведенное исследование показало важность учета физической нагрузки для детей с нарушениями интеллекта. На основании данных исследования были сформированы рекомендации по проведению физкультурных занятий.

Ключевые слова: дети с нарушением интеллекта, адаптивная физическая культура, психоэмоциональное состояние, стабилометрия.

Gimazov R.M.

ORCID: 0000-0001-5200-2321, Ph.D.;

Popova A.K.

Surgut State Pedagogical University,

Surgut, Russia

\section{THE INFLUENCE OF PHYSICAL EXERTION ON THE PSYCHO-EMOTIONAL CONDITION OF CHILDREN WITH INTELLECTUAL DISABILITIES}

Annotation. The article presents the results of stabilometric study to identify the impact of physical exertion on children with intellectual disabilities engaged in the Surgut School for Students with Disabilities. The study showed the importance of taking into account physical activity for children with intellectual disabilities. Based on the data of the study, recommendations for conducting physical education classes were formed.

Keywords: childrenwith intellectual disabilities, adaptive physical culture, psycho-emotional state, stabilometry.

На необходимость изучения методических особенностей проведения физкультурных занятий и выполнения контроля психоэмоционального состояния у детей с нарушением интеллекта в условиях реализации образовательного процесса в специализированных образовательных учреждениях посвящены работы ученых [3, 4, 5 и др.]. В них отражены наиболее общие подходы к изучению влияния средств адаптивного физического воспитания, направленных на коррекцию психоэмоционального состояния у детей среднего школьного возраста.

Коррекция психоэмоционального состояния детей с нарушениями интеллекта при помощи физических упражнений является действенным методом воздействия в деятельности 
учителя, однако неправильно рассчитанная физическая нагрузка на физкультурных занятиях может только ухудшить как физическое, так и психоэмоциональное состояние ребенка. Именно поэтому так важно изучить данный вопроси провести дополнительные исследования по влиянию физических нагрузок на общее состояние ребенка, имеющего интеллектуальные нарушения.

Цель. Определить методом стабилометрии влияние физических нагрузок на детей с нарушениями интеллекта, занимающихся в КОУ «Сургутская школа для обучающихся с ограниченными возможностями здоровья».

Методы и методика исследования. В основе исследования лежит методика проведения стабилометрии, разработанная Р. М. Гимазовым [1, 2]. Данная методика включает в себя предварительное измерение таких антропометрических данных как рост, длина стопы, расстояние между лодыжек и носков, ширина стопы, расстояние между подвздошными костями. После дети вставали на стабилоплатформу согласно установленной разметке в Европейскую стойку (пятки вместе, носки врозь) в состоянии покоя. Обследование требует, чтобы перед платформой на уровне глаз ребенка должен быть установлен наглядный ориентир куда учащиеся должны смотреть, для того чтобы они не могли отвлекаться и поворачивать голову по время обследования. На протяжении 51 сек учащиеся стоят прямо не двигаясь, смотря в указанную точку. После чего они закрывают глаза, фиксируют положение и продолжают стоять не двигаясь, на протяжении 51 сек. Далее, обучающиеся выполняют покачивание вперёд-назад без отрыва стоп от опоры прямым телом в медленном темпе так же на протяжении 51 сек. После каждой смены положения, учащемуся предоставляется время привыкнуть к положению (несколько секунд). После проведения третьей пробы учащиеся выполняют на протяжении 1 минуты 30 приседаний под заданный ритм метронома. Во время приседаний учащиеся решали простейшие математические задачи на сложение или вычитания. В них дети должны были в уме посчитать и озвучить математический результат. В случаях если обучающиеся не в состоянии или плохо освоили счет, то им показывали предметы, и такие дети должны были сказать каким цветом данный предмет. После приседаний дети встают обратно на платформу и проводится повторное стабилометрическое обследование в трех пробах - с открытыми, закрытыми глазами и в пробе покачиваний всем телом вперед-назад.

В обследовании приняло участие 6 учащихся с нарушениями интеллекта.

Результаты исследования и их обсуждение. Оценка влияния физической нагрузки на психоэмоциональное состояние детей велась по трем показателям - мышечная синергия, нервное напряжение, кинетическая чувствительность [1]. Данные показатели, выявляемые в ходе стабилометрического обследования позволяют дать полное представление о том, как испытуемый адаптирован к нагрузкам.

Рост показателя нервного напряжения указывает на активную реакцию нервной системы на физическую нагрузку, она заставляет испытуемого «взбодриться», уменьшение же этого показателя указывает на утомление нервной системы и неправильный выбор уровня физической нагрузки. Рост показателя мышечной синергии свидетельствует о более согласованной работе скелетных мышц (в том числе мышц стабилизаторов), испытуемый лучше держит равновесие, ощущает себя в пространстве. Снижение данного показателя после контролируемого воздействия указывает на чрезмерное влияние предъявляемой нагрузки на организм ребенка. Показатель кинетической чувствительности отражает способность нервной системы экономно организовать процесс построения движений в двигательных действиях. Улучшение данного показателя после предъявления ребенку физической нагрузки характеризует позитивную динамику приспособительных реакций нервно-мышечной системы 
у детей, а ухудшение - характеризует скрытые отрицательные признаки дезадаптивных реакций организма.

Таблица

Результаты стабилометрического обследования детей с нарушением интеллекта (6 чел)

\begin{tabular}{|c|c|c|c|c|c|c|c|c|c|c|c|c|}
\hline \multirow[t]{3}{*}{ ФИО } & \multicolumn{4}{|c|}{$\begin{array}{c}\text { Проба Ромберга с } \\
\text { открытыми глазами (51 сек) }\end{array}$} & \multicolumn{4}{|c|}{$\begin{array}{c}\text { Проба Ромберга с закрытыми } \\
\text { глазами (51 сек) }\end{array}$} & \multicolumn{4}{|c|}{$\begin{array}{c}\text { Проба Ромберга с } \\
\text { закрытыми глазами } \\
\text { покачиваясь вперед - назад } \\
\text { прямым телом без отрыва } \\
\text { стоп от опоры (51 сек) }\end{array}$} \\
\hline & \multicolumn{2}{|c|}{$\begin{array}{c}\text { Нервное } \\
\text { напряжение }\end{array}$} & \multicolumn{2}{|c|}{$\begin{array}{l}\text { Мышечная } \\
\text { синергия }\end{array}$} & \multicolumn{2}{|c|}{$\begin{array}{c}\text { Нервное } \\
\text { напряжение }\end{array}$} & \multicolumn{2}{|c|}{$\begin{array}{l}\text { Мышечная } \\
\text { синергия }\end{array}$} & \multicolumn{2}{|c|}{$\begin{array}{c}\text { Нервное } \\
\text { напряжение }\end{array}$} & \multicolumn{2}{|c|}{$\begin{array}{c}\text { Мышечная } \\
\text { синергия }\end{array}$} \\
\hline & 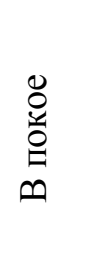 & 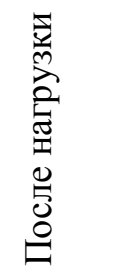 & $\begin{array}{l}\mathscr{0} \\
\text { 光 } \\
0 \\
\emptyset\end{array}$ & 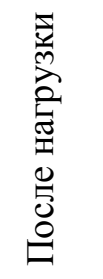 & 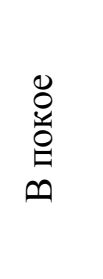 & 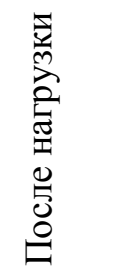 & 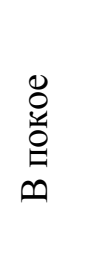 & 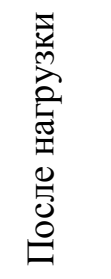 & $\begin{array}{l}\text { Oे } \\
\text { y̆ } \\
0 \\
0 \\
0\end{array}$ & 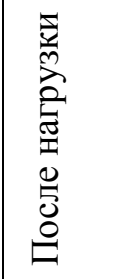 & 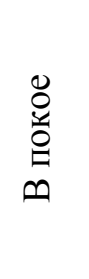 & 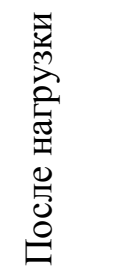 \\
\hline П.Д.А & 130 & 231* & 221 & $416^{*}$ & 315,5 & $469,5^{*}$ & 569 & $608^{*}$ & 11,5 & $12,5^{*}$ & 19 & $17,5^{* *}$ \\
\hline Т.В.И & 47,5 & 25 & 123,5 & 54 & 45 & $44 * *$ & 131 & 98 & 17 & $20 * *$ & 33 & 52* \\
\hline B.A.A & 339 & 219 & 725 & 663 & 643 & 289 & 1440 & 682 & 18,5 & $21,5^{*}$ & 43 & $44^{* *}$ \\
\hline E.K.A & 454,5 & 302 & 972 & 210 & 401,5 & 67 & 894,5 & 131 & 12,5 & $15^{*}$ & 18 & $25^{*}$ \\
\hline А.Г.А & 680 & 244,5 & 2396 & 821,5 & $\mathbf{3 3 9 , 5}$ & $447 *$ & 1120 & $1646^{*}$ & 24 & 16 & 92,5 & 56 \\
\hline Я.A.B & 23 & $22,5^{* *}$ & 99 & $73 * *$ & 27 & 16,5 & 58,5 & 46,5 & 16 & $23^{*}$ & $\mathbf{3 5 , 5}$ & $52,5^{*}$ \\
\hline
\end{tabular}

Примечание: полужирный шрифт числа и знак * - это положительные сдвиги; ** - без значимых изменений; обычный шрифт числа - отрицательные сдвиги

Из результатов эксперимента следует, что только у одного испытуемого (П.Д.А.) наблюдалась положительная динамика приспособительных реакций нервно-мышечной системы на предъявленный уровень физической и умственной нагрузки.

У остальных детей наблюдалось в основном отрицательная динамика приспособительных реакций нервно-мышечной системы на предъявленный уровень физической и умственной нагрузки за исключением отдельных частных случаев, которые могли наблюдаться в двигательных действиях, требующих либо статический контроль баланса, либо динамический.

Bblвoдbl. Таким образом, стабилометрическое обследование детей с нарушениями интеллекта позволило установить, что только один воспитанник специализированного образовательного учреждения адекватно приспосабливается к нагрузкам на физкультурных занятиях. С учетом результатов проведенного исследования к остальным детям следует внимательнее отнестись педагогу на физкультурных занятиях. Процесс коррекции психоэмоционального состояния детей с нарушениями интеллекта при помощи физических упражнений нуждается в точных рекомендациях для проведения занятий. Эти данные позволяют нам оценить влияние нагрузок на детей и грамотно распределять роли среди детей, например, в подвижной игре. Так из обследуемых детей только ученик П.Д.А. может и должен выполнять роль ведущего, а вот остальным детям должны быть предоставлены роли ведомых в игре. Именно им из-за сниженного уровня интеллектуальных и физических нагрузок в роли ведомого такой уровень предъявляемых нагрузок будет адекватным на физкультурных занятиях. 
Применяя данные рекомендации, педагог для детей нарушениями интеллекта сможет точнее выбрать необходимый уровень нагрузки и таким образом контролировать у них психоэмоциональное состояние.

\section{Литература}

1. Гимазов Р.М. Ловкость и технология формирования техники двигательного действия // Издательские решения, 2020.

2. Гимазов Р.М. Стабилометрические показатели, характеризующие состояние центральных и периферических структур нервно-мышечного аппарата организма спортсменов // Ученые записки университета имени П.Ф. Лесгафта. 2012. №10. С. 43-48.

3. Ильенко О.В., Левченко Т.С. Психолого-педагогическое сопровождение детей с интеллектуальными нарушениями. Университетская наука. 2019. №2 (8). С. 163-166.

4. Колосова Т.А., Исаев Д.Н. Психология детей с нарушением интеллекта: учебное пособие для бакалавриата и специалитета. 2-е изд., перераб. и доп. М.: Изд-во Юрайт, 2019. $151 \mathrm{c}$.

5. Литвина Г.А., Кульчицкий В.Е., Кузакова А.А. Необходимость адаптивной физической культуры для детей с нарушениями интеллекта. Тенденции развития науки и образования. 2020. №59-4. С. 20-22.

(C) Гимазов Р.М., Попова А.К., 2021 